\title{
Study of Patient Satisfaction with Persian Medicine in Referrals to Behesht Persian Medicine Clinic of Iran University of Medical Sciences in 2016
}

\author{
Hoorieh Mohammadi Kenari ${ }^{1}$, Maryam Taqavi Shirazi ${ }^{1}$, Rozita Jafari ${ }^{2}$ and Maryam Moghimi ${ }^{3 *}$ \\ ${ }^{1}$ Research Institute for Islamic and Complementary Medicine, Iran University of Medical Sciences, Tehran, Iran \\ ${ }^{2}$ School of Health Management and Information Sciences, Iran University of Medical Sciences, Tehran, Iran \\ ${ }^{3}$ Persian Medicine Offices of Ministry of Health and Medical Education, Tehran, Iran
}

\begin{abstract}
Background: Today, complementary and alternative medicine and a variety of traditional medicine, along with conventional medicine, are used to prevent and treat diseases. In Iran, Persian medicine is taught academically and its services are being provided to patients. The aim of this study is to evaluate the patient satisfaction with Persian medicine and the reasons for follow up or non-follow-up of treatment by patients referred to Behesht Persian medicine clinic of Iran university of Medical Sciences.
\end{abstract}

Methods: 394 cases were selected among patients who were treated by Persian medicine in the Behesht clinic in 2016. After extracting the data, a semi structured questionnaire regarding the degree of satisfaction with the treatment and the reasons for follow up or non-follow up of the patients was completed by making phone calls with participants. Data were then analyzed using software (Microsoft Excel 2016).

Results: Women were referred to the Persian medicine clinic more than men $(72.5 \%$ versus $27.5 \%)$. The most common causes of referral were gastrointestinal diseases (15.1\%) and musculoskeletal disorders (13.5\%). $35 \%$ of the patients referred only once and did not follow the treatment. The most common causes of non-referral were the patient's own lack of attention to taking medication and follow-up (24.2\%), disease recovery (23\%), lack of appropriate response to treatment $(20.8 \%)$ and relocation of the therapist $(11.6 \%) .91 .4 \%$ of participants did not mention any complications and $95.84 \%$ were satisfied with the behavior of doctors. Overall, $82.6 \%$ of patients had a tendency to recurrent referral to the clinic.

Conclusion: Despite the problems with referral of patients to the Persian medicine clinic, there is a high inclining rate that reflects the satisfaction of the treatment. Therefore, planning to solve existing problems and facilitating the referral of patients can increase the satisfaction rate of Persian medicine. More studies are needed in other Persian medicine centers to evaluate patients' satisfaction

Keywords: Persian medicine; Patient satisfaction; Referral; Treatment

\section{Introduction}

Today, complementary and alternative medicine and a variety of traditional medicine, along with conventional medicine, are used to treat and restore health to sick people and prevent disease in healthy people or to enhance the quality of life, which is evidence of a promising future in this area $[1,2]$. Given that conventional therapies are based on traditional methods in health care systems, there is an increasing need to study and evaluate the effectiveness of these treatments [3]. On the other hand, since traditional medicine, complementary or alternative therapies have been formed in different cultures and different regions, their standards and methods of assessment, both at the national and international levels; have not been sufficiently developed [4].

Persian Medicine consists of the sum total of all the knowledge and practices used in diagnosis, prevention and elimination of diseases in Persia from ancient times to present. It seems that Persian scholars first conceived the theory of humors and then it became a world wild theme of medicine later. This theory was based on four humors including blood, phlegm, black bile and yellow bile which were the basis of diagnosis and treatment in that time [5]. Persian medicine is now provided in Iran by physicians who have passed the course of conventional medicine and can approach to the patient after considering his/her attitude and consent about the treatment method. Dealing with conventional medicine, Persian medicine can solve many health and medical problems, due to the history of several hundred years and high capacity of prevention and treatment [6].

In Persian medicine, in addition to abundant books containing valuable experiences of Iranian scholars that has been transmitted and used from generation to generation, in many references, examples of case reports or case series are available [7-9]. However, the important point in health systems is evidence gathering in certain frameworks and preferably randomized clinical trial studies. Unfortunately, the effects and responses to treatment in many cases of Persian medicine are not well understood in these frameworks, and research on their therapeutic effects is under development. Also, the limitations of the research method, such as low sample size, inappropriate control and

${ }^{*}$ Corresponding author: Maryam Moghimi, Persian Medicine Office of Ministry of Health and Medical Education, Tehran, Iran, Tel: 982181454465; E-mail mmoghimi60@yahoo.com

Received December 18, 2017; Accepted December 29, 2017; Published January 08, 2018

Citation: Kenari HM, Shirazi MT, Jafari R, Moghimi M (2018) Study of Patient Satisfaction with Persian Medicine in Referrals to Behesht Persian Medicine Clinic of Iran University of Medical Sciences in 2016. Altern Integ Med 7: 257. doi: 10.4172/2327-5162.1000257

Copyright: (c) 2018 Freti L, et al. This is an open-access article distributed under the terms of the Creative Commons Attribution License, which permits unrestricted use, distribution, and reproduction in any medium, provided the original author and source are credited. 
non-specific interventions, prevent the extension of the results [10-12]. Critics of complementary medicine also insist on the lack of evidence to support these therapies $[13,14]$.

In Iran, in recent years, there have been many studies about the impact and effectiveness of Persian medicine fundamentals and treatments, some of which have led to confirmation, and some have rejected these outlooks [15-32].

Since Persian medicine is nowadays academic in Iran, it is essential to validate, assess and evaluate what is presented. Since it has not been a long time that this course entered the university, research in this field requires guidance and prioritization for a variety of topics. Also, despite the significant development of the use of traditional medicine around the world, measuring the efficiency and benefits of traditional therapies is important for health care providers and health policymakers. In this article, which can initiate the next extensive studies, the patient satisfaction with Persian medicine and the reasons for follow up or nonfollow-up of treatment by patients referred to Behesht Persian medicine clinic of Iran university of Medical Sciences is discussed.

\section{Materials and Methods}

This study was conducted at Behesht Persian Medicine clinic of Iran University of Medical Sciences in Tehran.

394 cases were randomly examined from patients who were visited in Behesht clinic in 2016. The first visit documents were reviewed for each patient and the following data were extracted:

- Demographic characteristics

- The patient's chief complaint

- Therapeutic protocols (including dietary, medication, lifestyle modification and manual treatments)

Then, a semi structured questionnaire prepared by using the articles and previous experiences of Iranian professors, was fulfilled. Questions were asked from patients by telephone. Anyone who was not able to answer or was not available was excluded from the study. The questions were asked from the patient him/herself.

Each patient was followed up at least 6 months after the first visit. Causes of referral or non-referral of patients to the clinic for the second visit were asked by telephone. Then the collected data was analyzed using inferential statistics and Microsoft Excel 2016 software.

\section{Results}

In general, 393 cases of 5325 patients visited at Behesht Clinic in 2016 were randomly selected and studied. 317 of them were called by phone. In spite of repeated attempts to call with 76 patients, it was not possible. Of these, the mobile set of 20 patients were off, 30 of them did not cooperate with the researcher and did not answer the questions, the phone numbers of 15 were not registered in the file, and 11 had wrong phone numbers. The mean age of patients was $40.7 \%$ of which $27.5 \%$ were male and $72.5 \%$ were female (Table 1 ).

Of the 317 cases reviewed, 114 were new patients who had only one visit, 72 were visited twice, and 81 had three visits. Also, 50 participants were visited more than 3 times (Table 2).

In general, the patients presented various reasons for their lack of recurrence, the most common ones were the patient's own lack of attention to taking medication and follow-up (24.2\%), disease recovery (23\%), lack of appropriate response to treatment (20.8\%), relocation of the therapist (11.6\%), the intention of the patient to referral due to satisfaction with the treatment $(10.09 \%)$, residence in a distant city from the clinic (3.1\%) and treatment complications (2.2\%) (Table 3). Chart 1 represents the most common causes of non-referral of patients to the clinic and chart 2 shows all of the factors reported by patients as the cause of non-referral.

In a survey of a total of 317 cases, the main complaint that led to referral to the Persian medicine clinic was digestive diseases (48 cases), musculoskeletal disorders (46 cases) and skin diseases (42 cases).

Of course, some complaints such as overweight or excessive weight loss or systemic diseases, such as diabetes and hypertension, etc. which was also categorized as general disorders, were the most common complaints with a total of 56 cases. Also, 10 cases were referred for cupping or massage therapy, as well as determination of the temperament which were categorized as miscellaneous diseases. Table 4 explains the patient complaints based on organ involvement.

Among the digestive disorders, flatulence with 73 cases and constipation with 66 cases were the most common complaints of patients (Figures 1 and 2). Among musculoskeletal diseases, various

\begin{tabular}{|c|c|c|}
\hline Participants & Amplitude & Percent \\
\hline Male & 87 & 27.5 \\
\hline Female & 230 & 72.5 \\
\hline Total & 317 & 100 \\
\hline
\end{tabular}

Table 1: Frequency of participants by gender.

\begin{tabular}{|c|c|c|}
\hline Visit time & Frequency & Percent \\
\hline Once & 114 & 35 \\
\hline Twice & 72 & Jul-22 \\
\hline 3 times & 81 & May-25 \\
\hline More than 3 times & 50 & Jul-15 \\
\hline
\end{tabular}

Table 2: Frequency of visit times of patients.

\begin{tabular}{|c|l|c|}
\hline & Cause of non-referral & Percent \\
\hline 1 & patient's own lack of attention to taking medication and follow-up & 24.2 \\
\hline 2 & disease recovery & 23 \\
\hline 3 & lack of appropriate response to treatment & 20.8 \\
\hline 4 & relocation of the therapist & 11.6 \\
\hline 5 & $\begin{array}{l}\text { satisfaction with the treatment (the patient intends to be visited } \\
\text { again) }\end{array}$ & 10.09 \\
\hline 6 & Residence in a distant city from the clinic & 3.1 \\
\hline 7 & Treatment complications & 2.2 \\
\hline
\end{tabular}

Table 3: The most common causes of non-referral of patients to the clinic.

\begin{tabular}{|l|c|c|}
\hline Chief complaint of the participants & Number & Percent \\
\hline Skin, hair and nail diseases & 42 & 13.2 \\
\hline Eye diseases & 2 & 0.6 \\
\hline Ear, nose and throat (ENT) diseases & 14 & 4.4 \\
\hline Neurologic diseases & 22 & 6.9 \\
\hline Psychiatric diseases & 20 & 6.3 \\
\hline Heart diseases & 4 & 1.2 \\
\hline Disease of respiratory system & 11 & 3.4 \\
\hline Digestive diseases & 48 & 15.1 \\
\hline Urogenital diseases & 8 & 2.5 \\
\hline Musculoskeletal disorders & 44 & 13.8 \\
\hline Gynecologic diseases & 36 & 11.3 \\
\hline General disorders & 56 & 17.6 \\
\hline Miscellaneous diseases & 10 & 3.1 \\
\hline
\end{tabular}

Table 4: Frequency of complaints of patients referring to the clinic. 
Citation: Kenari HM, Shirazi MT, Jafari R, Moghimi M (2018) Study of Patient Satisfaction with Persian Medicine in Referrals to Behesht Persian Medicine Clinic of Iran University of Medical Sciences in 2016. Altern Integ Med 7: 257. doi: 10.4172/2327-5162.1000257

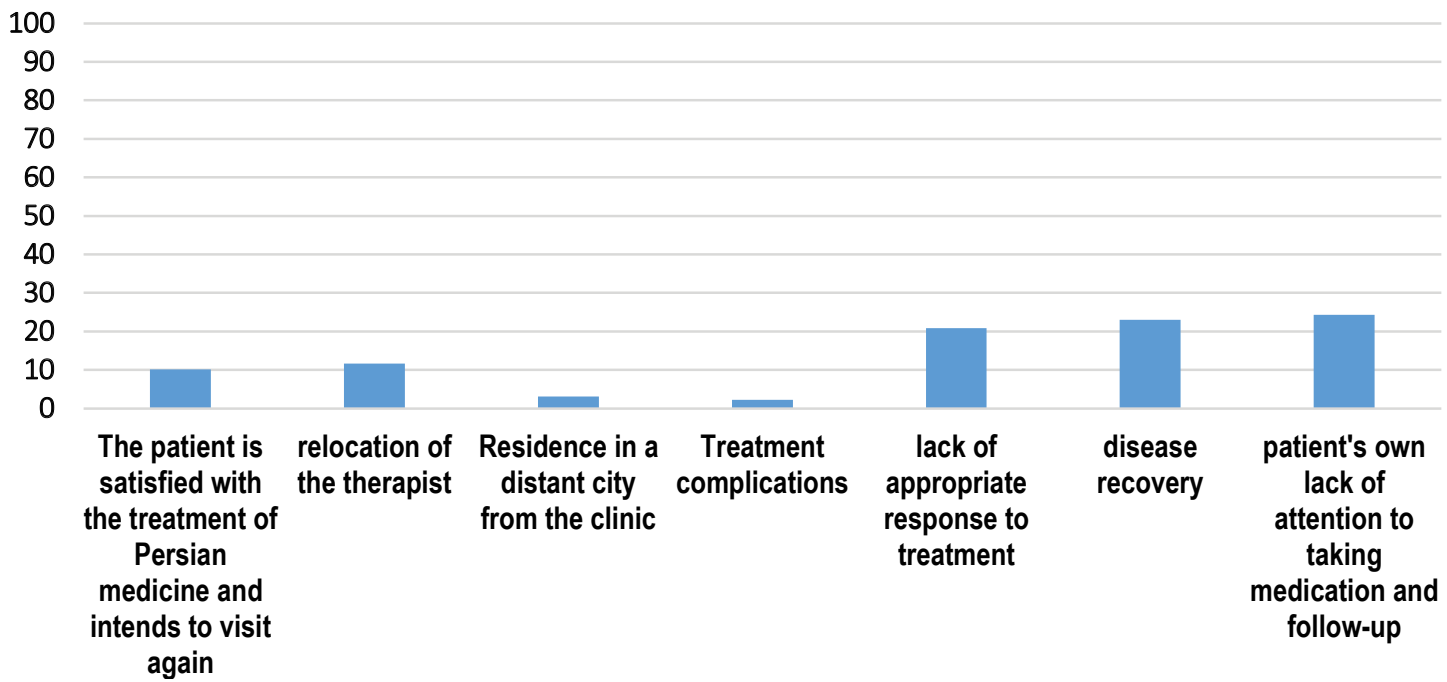

Figure 1: The columnar chart of the most common causes of non-referral of patients to the clinic.

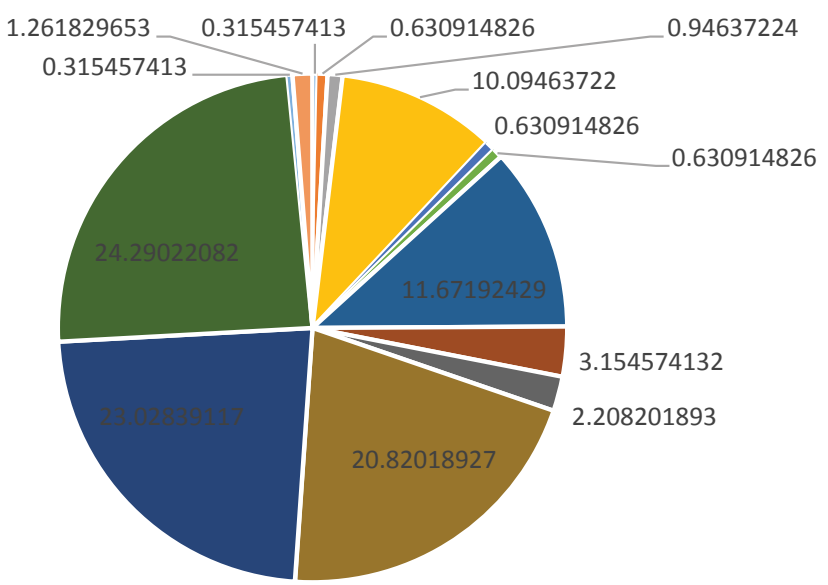

- Recurrence of illness after the end of treatment

- The difficulty of performing treatment recommendations

- personal problems

vatisfaction with the treatment, the patient intends to be visited again

- Interruption of the visit time with the time of attending school

- Patient dissatisfaction with treatment due to the number of prescribed drugs

- relocation of the therapist

- Residence in a distant city from the clinic

- Treatment complications

- lack of appropriate response to treatment

- disease recovery

- patient's own lack of attention to taking medication and follow-up

- Patient dissatisfaction with the doctor

- expensive drugs of Persian medicine

Figure 2: The pie chart of all factors reported by patients as the cause of non-referral. 
joint pains with 38 cases and muscle spasm with 12 cases were the most common complaints. The most prevalent complaints in skin diseases were skin dryness with 18 cases, itching and hair loss with 7 cases. Headache with 29 cases and stress disorders with 35 cases were the most common complaints among neurological and psychiatric diseases. Some of the most prevalent complaints related to each organ are listed in Table 5.

It was found out about compliance with the recommendations that 69 patients had better observance of lifestyle modification and dietary measures, 215 had a tendency to use drugs, 20 had better performed manual treatments, and 13 did not comply with any of the treatments (Table 6).

In reviewing the possible complications caused by measures and medications, no complication of lifestyle modification was reported. 24 participants believed that they had drug complications however the type of complication did not be revealed. 3 cases also believed that they were affected by the complications of cupping therapy or other manual treatments and 290 reported no complications (Table 7).

Patients were also asked about satisfaction with the manner and behavior of physicians. 2 patients were dissatisfied with that while 11 reported tolerable behavior of physicians. The rest of the participants were satisfied with the manner of the physicians (Table 8).

\begin{tabular}{|c|c|c|}
\hline System & chief complaint & Frequency \\
\hline \multirow{3}{*}{ nervous system } & Headache & 29 \\
\hline & Memory disorders & 9 \\
\hline & Dizziness and true vertigo & 5 \\
\hline \multirow{3}{*}{ Psychiatry } & Stress disorders & 35 \\
\hline & Depression & 8 \\
\hline & Obsessive compulsive disorder & 6 \\
\hline \multirow{2}{*}{ Cardiovascular system } & Palpitation & 17 \\
\hline & Chest pain & 3 \\
\hline \multirow{6}{*}{ Digestive system } & Flatulence & 73 \\
\hline & Constipation & 66 \\
\hline & Stomach ache & 11 \\
\hline & Regurgitation & 10 \\
\hline & Excessive thirst & 13 \\
\hline & Nausea & 12 \\
\hline \multirow{3}{*}{ Musculoskeletal system } & Arthralgia & 38 \\
\hline & Muscle spasm & 12 \\
\hline & Leg pain & 7 \\
\hline \multirow{3}{*}{ Gynecology } & Menstrual disorders & 11 \\
\hline & Ovarian cyst & 7 \\
\hline & Uterine fibroids & 7 \\
\hline \multirow{2}{*}{ Urogenital system } & Urine frequency & 9 \\
\hline & Dysuria & 4 \\
\hline \multirow{4}{*}{ Skin and hair } & Skin dryness & 18 \\
\hline & Itching & 7 \\
\hline & Hair drop & 7 \\
\hline & Acne & 6 \\
\hline \multirow{2}{*}{ Respiratory system } & Allergy & 5 \\
\hline & Cough & 3 \\
\hline \multirow{2}{*}{ ENT } & Post nasal discharge (PND) & 50 \\
\hline & Sinusitis & 6 \\
\hline \multirow{2}{*}{ Eye } & Low vision & 1 \\
\hline & Xerophthalmia & 1 \\
\hline \multirow{3}{*}{ General } & Chronic fatigue & 26 \\
\hline & Diabetes mellitus & 9 \\
\hline & Anemia & 12 \\
\hline
\end{tabular}

Table 5: Frequency of the most common complaints related to each system.

\begin{tabular}{|l|c|c|}
\hline Measures & Frequency & Percent \\
\hline Lifestyle modification & 69 & 21.7 \\
\hline Drug therapy & 215 & 67.8 \\
\hline manual treatments & 20 & 6.3 \\
\hline Failure to observe any measures & 13 & 4.1 \\
\hline
\end{tabular}

Table 6: Frequency of observance of therapeutic recommendations by patients.

\begin{tabular}{|l|l|l|}
\hline complication & frequency & Percent \\
\hline No complications & 290 & 91.4 \\
\hline Drug complications & 24 & 7.5 \\
\hline Manual treatment complications & 3 & 0.9 \\
\hline
\end{tabular}

Table 7: Frequency of complications caused by Persian medicine treatments.

\begin{tabular}{|l|c|c|}
\hline Manner of physician & frequency & Percent \\
\hline Too bad & 1 & 0.3 \\
\hline Bad & 1 & 0.3 \\
\hline Tolerable & 11 & 3.4 \\
\hline Good & 288 & 90.8 \\
\hline Very good & 16 & 5.04 \\
\hline
\end{tabular}

Table 8: Frequency of patient satisfaction with the manner and behavior of physicians.

\begin{tabular}{|c|c|c|}
\hline Patient tendency & Frequency & Percent \\
\hline Yes & 262 & 82.6 \\
\hline No & 52 & 16.4 \\
\hline abstainer & 3 & 0.9 \\
\hline
\end{tabular}

Table 9: Frequency of patient tendency to referral to the clinic.

Patients were asked about the tendency to referral to the clinic and follow-up treatment of which 262 participants tended to referral, 52 were uninterested and 3 did not answer this question (Table 9).

\section{Discussion}

In this study, $26.5 \%$ of participants were male and $72.5 \%$ were female which indicates that women are more likely to go to the Persian medicine clinic than men. Of course, this is not necessarily due to more incidence of disease in women or their more interest in Persian medicine, but since this study included reviewing the patient records of morning shift of the clinic, the educational shift, the referral of employed people to the clinic was less frequent at this time. The evidence is that several patients reported interruptions in the time of attendance at the clinic by working hours or school hours as a reason for not referring.

Regarding the frequency of visits, it should be noted that in Persian medicine, it is necessary for the patient to see his/her doctor several times. The purpose of those recurrent visits is to perform more diagnostic examinations and follow-up treatment. It means that sometimes, in the first visit, there are several distinct diagnoses requiring laboratory tests and medical imaging to achieve a definite diagnosis. Therefore, this should be considered in recurrent referrals. In many cases, it is necessary for the physician to assess the response to treatment within a certain period of time and based on this, he/she will make the necessary changes in approach to the patient. Therefore, in multi-stage therapies or in order to complete the logical follow-up of the treatment, referral is necessary and recommended. In these cases, recurrent referrals also increase the validity of treatment, however if the patient avoid referral to the doctor, misdiagnosis or incomplete treatment may occur which will lead to wasting of the cost and time of the patient, the doctor and the clinic, and unwanted complications may happen during this time. On the other hand, recurrent referrals may indicate that the patient has not been treated thoroughly and correctly. 
In fact, there would be an error, a mistake or a problem in the treatment of the patient. Considering that the purpose of any medical activity is to reduce the incidence of disease and increase the outcome to the benefit of the patient, this kind of recapitulated referral means that capital, manpower, and equipment in the process of these activities are wasted without proper result. In addition, the patient will use the facilities that are considered for another patient when referring again [33]. Therefore, referral of patients should be targeted, i.e., useful and necessary referrals should be increased and referrals that are due to errors or mistakes or other problems should be reduced. Preventive factors should be identified to reduce the number of unwanted visits. Instead, we need to increase the number of referrals that are needed to followup and complete the treatment. In this study, 114 patients had only one visit, 21 of whom had been treated, and the rest were dissatisfied with the continuation of treatment for various reasons, which could lead to waste of time and energy for physicians and patients themselves. Therefore, recommendation and emphasis on referral by the doctor can be a useful way to encourage patients to continue their treatment. Other patients who did not have recurrence indicated various reasons such as lack of attention to taking medication, relocation of the physician, the cost of treatment, dissatisfaction with the type of treatment offered and long distance of clinic from the home, as a cause of non-attendance.

In general, the most prevalent chief complaints reported in this study were digestive problems and musculoskeletal disorders. In the study of Mohammadian et al. [6] in Isfahan, the most common cause for referral is low back pain and fatigue. In a study in Sweden, musculoskeletal disorders are the first cause of referral, followed by respiratory, cardiovascular and digestive disorders [34]. Therefore, it seems that the majority of patients referring to traditional medicine clinics in different regions are patients with musculoskeletal disorders as well as gastrointestinal problems. Perhaps one of the reasons of why gastrointestinal diseases are more common in traditional medicine clinics is the therapists' emphasized attention to these problems and getting a more accurate digestive history. After gastrointestinal diseases, musculoskeletal disorders were just the most common complaints of patients that were consistent with the findings of conventional medicine. Arthritis is the second complaint of outpatient complaints in conventional medicine, and affects about $10 \%$ of the total human population as a result of chronic pain and inflammation of the joints [35-37]. Although this disease is not fatal, most patients, if left untreated, would suffer from chronic pain and complicated problems until the end of their life [24]. The most important remedy for this disease is prevention and lifestyle changes. Considering that there is currently no definitive treatment for this condition in conventional medicine and the pyramid of the population is also indicative of population aging, it seems that the use of preventive and therapeutic methods of Persian medicine are helpful for reducing the rate and severity of pain and symptoms of patients. This issue should be further investigated in future studies. Appropriate diet and healthy lifestyle are needed for every individual at any time of life. In this study, despite the fact that nobody had any problem or complication from the lifestyle modification, the rate of welcoming patients was lower and they tended to take drugs and pills. Because compliance with diet and lifestyle measures was difficult for patients due to the widespread of invalid lifestyle and even some who fully complied with the orders complained about it. Therefore, it is better to emphasize the patients that their current lifestyle is harmful to the health, and they need to change their lifestyle habits forever. In this case, patients will be less likely to complain of the difficulty of observing the measures.

The reason that some patients reported adverse drug reactions without knowing the type of complication was a defect in our questionnaire. Because from the Persian medicine point of view, the complications noted by patients can sometimes be part of the effects of the drug and is not a complication, such as disposal of waste substance through the intestines as diarrhea that patients mistakenly interpret it as a drug side effect. Such a defect must be corrected in future questionnaires.

In this study, it was found that satisfaction with the behavior of physicians was also desirable.

The following results are found from the review of various articles about patients' satisfaction with traditional and complementary therapies:

In a study conducted in Italy, the satisfaction of those who used the complementary method was evaluated and it was shown that the most of referrals are middle-aged women with higher education and social status and the most satisfaction is seen in this group [38]. In evaluating the satisfaction of referrals to traditional Chinese medicine in Switzerland, the satisfaction of those who used both conventional medicine and complementary therapies is higher than those who used only conventional medicine. This difference is due to fewer side effects of traditional Chinese medicine, better doctor-patient relationship, longer care times, and a variety of patient-facing therapies [39]. In a study in Isfahan, the satisfaction of patients with acupuncture is also good [40]. In the study of Rossi et al. the effectiveness of complementary therapies on cluster headaches was observed, and satisfactory patient satisfaction is observed with complementary therapies and treatment costs [41]. A study in Germany reported that complementary medicine has been effective in preventing many diseases, including cardiovascular disorders, migraine and Alzheimer [42]. A review article by Furlan et al. [43] about the effectiveness of complementary medicine on neck and low back pain has confirmed its real impact. Of course, complementary medicine and alternative medicine did not reduce the relative disability compared to the control group. In our study, the majority of patients tended to refer to the clinic and follow up treatment, which indicates the satisfactory patient satisfaction with Persian therapies in the Behesht Clinic.

As previously stated, long distance of the clinic from the patient's residence was one of the reasons for not referring patients to the clinic, which could lead to a lack of re-prescription of the drug and discontinuing the treatment. Therefore, development of Persian medicine clinics and the fair distribution of drugs in the city or even at the national level is necessary. Reliable and extensive research on Persian medicine drugs will validate these drugs and pharmacies will be more likely to sell them. Also, the number of people who are reluctant to use Persian therapies due to uncertainty about them will be reduced.

Another problem that some people complained about was the high cost of treatment. Especially those who fully complied with the treatments were dissatisfied with the cost of providing medications. Therefore, given the long duration of treatment in Persian medicine, it is imperative that policy makers of the health system and Persian medical managers provide certain solutions to insure the Persian medicine services and herbal drugs.

Because of dissimilarity of the treatments, evaluation of the treatment efficacy could not be verified, which should be investigated in subsequent studies in specialized and categorized groups.

\section{References}

1. Goldbeck-Wood S, Dorozynski A, Lie LG (1996) Complementary medicine is booming worldwide. BMJ 313: 131-133. 
Citation: Kenari HM, Shirazi MT, Jafari R, Moghimi M (2018) Study of Patient Satisfaction with Persian Medicine in Referrals to Behesht Persian Medicine Clinic of Iran University of Medical Sciences in 2016. Altern Integ Med 7: 257. doi: 10.4172/2327-5162.1000257

Page 6 of 6

2. WHO Traditional Medicine (2003) Report by the Secretariat. Fifty-sixth world health assembly A56/18, Provisional agenda item 14.10.

3. Ardakani SM, Farjadmand F (2006) General guidelines for methodology in the field of traditional medicine research. Traditional Medicine research center of Shahid Beheshti University of Medical Sciences. Tehran.

4. Moradi lakeh M, Goosheh Gir A, Amini M (2008) Tendency to the topic of complementary /alternative traditional medicine in dissertation research (13701385). Payesh quarterly journal $7: 33-44$

5. Larijani B, Esfahani MM, Moghimi M, Ardakani SM, Keshavarz M, et al. (2015) Common types of diabetic dosage forms in medieval Persia. Pharm Hist (Lond) 45: 96-99.

6. Mahmoodian A, Golshiri P, Rezaee G, Akbari M (2012) Investigating the causes of referral and satisfaction of the traditional medicine users in Isfahan. Journal of Isfahan University of Medical Sciences 30:1550-1558.

7. Razes (2001) Al Havi [Liber Continent]. Ehyaol Toras al-Arabi Press. Beiruot.

8. Ahvazi A (2008) Kamel-al-Sanaat Al Tebiyah. Natural Medicine revival institute Tehran.

9. Baha Al-dolah Razi (2009) Kholasat Al-Tajarob. Tehran University of medical sciences press. Tehran.

10. Rains JC, Penzien DB (2005) Behavioral research and the double-blind placebo controlled methodology: Challenges in applying the biomedical standard to behavioral headache research. Headache 45: 479-486.

11. Rains JC, Penzien DB, Mc Crory DC, Gray RN (2005) Behavioral headache treatment: History, review of the empirical literature, and methodological critique. Headache 45: S92-S109.

12. Bloom BS, Retbi A, Dahan S, Jonsson E (2000) Evaluation of randomized controlled trials on complementary and alternative medicine. Int $\mathrm{J}$ Technol Assess Health Care 16: 13-21.

13. Marcus DM (2002) Alternative medicine and the Arthritis. Foundation. Arthritis Rheum 47: 5-7.

14. Fitzcharles MA (2002) Is it time for rheumatologists to rethink the use of manual therapies? J Rheumatol 29: 1117-1120.

15. Mozafari Khosravi H, Jalali B, Afkhami M (2008) The Effect of Sour Tea on Glucose, lipid Profile and Lipoproteins in diabetic patients. J Endocrinol Metab 10: $589-597$

16. Asgari S, Rahimi P, Madani H, Mahzooni P, Kabiri N (2008) Effect of Juglans regia hydroalcoholic extract on the prevention of type 1 diabetes in adult male rats. Iranian J Diabet Lipid 7: 363-370.

17. Zadeh NH, Safari M, Khoshnevisan F (2005) Study of the Effect of Herbal Medicines on Neonatal Hyperbilirubinemia: In vitro. Iranian Children's Dis J 15: 133-138.

18. Kalantari Z, Jafari H (2006) Survey of Extract of White Cabbage in Prevention and Treatment of Peptic Ulcer Caused by aspirin in rats. Jour Guilan Uni Med Sci 15: 89-94.

19. Avijgan M, Saadat M, Zadeh NM, Hafizi M (2006) Antifungal Effect of Echinophora platyloba extract on Several Common Dermatophytes. Med Herb Quart J 5: 10-16.

20. Izadi j, Sharif M, Khalilian A, Jaribi ZHH, Azad Bakht M, et al. (2003) Evaluation of anti-parasite effects of Achillea Millefolium on mouse ocxir parasites. J Mazandaran Uni Med Sci 13: 27-35.

21. Bandegi AR (2002) Evaluation of the effect of manna of Alhaji on blood bilirubin in mice with experimental Hyperbilirubinemia. J Semnan Uni Med Sci 2: 161-166.

22. Ghotbi F, Nahidi S, Zangi M (2006) Effect of Clay Milk on Neonatal Jaundice Reduction. J Shahid Beheshti University of Medical Sciences 31: 347-352.

23. Kenari MH, Arabshahi SK, Bigdeli S, Ardakani SM (2011) Explaining the concept of citation of evidence in Persian medicine from the point of view of the experts of this field. J Trad Med Islam and Iran 2: 203-214.

24. Mehdi Barzi D, Naseri M, Zadeh FS, Nejad KM, Bahrami M (2008) Double-blind clinical trial of Marham e Mafasel with placebo control in patients with knee osteoarthritis. Daneshvar Journal 16: 1-2.

25. Fani A, Ghasedi M, Lion A, Alizadeh B (2010) The effect of turmeric on improving the clinical symptoms of patients with irritable bowel syndrome. Arak Uni Med Sci 13: 109-115.

26. Akhondzadeh $S$, Noroozian $M$, Mohammadi M, Ohadinia S, Jamshidi AH, et al. (2003) Salvia officinalis extract in the treatment of patients with mild to moderate Alzheimer's disease: a double blind, randomized and placebocontrolled trial. $J$ Clin Pharm Ther 28: 53-59.

27. Abed A, Minaiyan M, Ghannadi A, Mahzouni P, Babavalian MR (2012) Effect of Echium amoenum Fisch. Et Mey a Traditional Iranian Herbal Remedy in an Experimental Model of Acute Pancreatitis. ISRN Gastroenterol 14158

28. Bonjar S (2004) Evaluation of antibacterial properties of some medicinal plants used in Iran. J Ethnopharmacol 94: 301-305.

29. Ahmadi A, Schwebel DC, Rezaei M (2008) The Efficacy of Wet-Cupping in the Treatment of Tension and Migraine Headache, Am J Chin Med 36: 37-44.

30. Taavoni S, Dorsareh F, Joolaee S, Haghani H (2012) The effect of massage therapy on physical signs of menopause 2: 21-28.

31. Siroos A, Khaki M, Goodarzi D (2007) Investigating the effect of capsule made from internal layer of chicken gizzard in treatment of urinary stones. J Arak Un Med Sci 10: 12-17

32. Jozi M, Amini R, Noorbakhsh V (2009) The Effect of Massage Therapy on Blood Pressure in Patients with 19: 261-265.

33. Khoshkam M (1994) Investigating the Causes of Patients' Referral to General Hospitals Affiliated to Iran University of Medical Sciences and Health Services. Thesis of Master for medical records, Iran University of Medical Sciences. Tehran.

34. Al-Windi A (2004) Determinants of complementary alternative medicine (CAM) use. Complement Ther Med 12: 99-111.

35. Koopman WJ (2001) Arthritis \& allied Conditions. Lippincott William's and Wilkin Press, Philadelphia, USA.

36. Chapman MW (2001) Chapman's orthopaedic Surgery. Lippincott William's \& Wilkins Press, Philadelphia, USA.

37. Klippel J, Dieppe P (1995) Practical Rheumatology. Mosby Press, USA

38. Barbadoro P, Chiatti C, D’Errico MM, Minelli A, Pennacchietti L, et al. (2011) Complementary and alternative medicine (CAM) among adults in Italy Use and related satisfaction. Eur J Integr Med 13: e325-e332.

39. Michlig M, Ausfeld-Hafter B, Busato A (2008) Patient satisfaction with primary care: a comparison between conventional care and traditional Chinese medicine. Complement Ther Med 16: 350-358

40. Mahmoodian SA, Babaee EM, Jafari M (2011) Referral causes and satisfaction of users of Acupuncture in Isfahan. Journal of Isfahan University of Medical Sciences 29: 2280-2288

41. Rossi P, Torelli P, Di LC, Sances G, Manzoni GC, et al. (2008) Use of complementary and alternative medicine by patients with cluster headache: results of a multi-centre headache clinic survey. Complement Ther Med 16 : 220-227.

42. Kraft K (2009) Complementary/Alternative Medicine in the context of prevention of disease and maintenance of health. Prev Med 49: 88-92.

43. Furlan AD, Yazdi F, Tsertsvadze A, Gross A, van Tulder M, et al. (2012) A systematic review and meta-analysis of efficacy, costeffectiveness, and safety of selected complementary and alternative medicine for neck and low back pain. Evid Based Complement Alternat Med 953139. 